\title{
Effect of Isomeric Oxydiphenylene Diamine on the Water Sorption Behavior of High Temperature Polyimide Thin Films
}

\author{
Jongchul Seo, Haksoo $\mathrm{HAN}^{\dagger}$, Anna LeE, \\ and Jungsoo HAN* \\ Department of Chemical Engineering, Yonsei University, 134 Shinchon-Dong, \\ Sedaemun-Gu, Seoul 120. 749, Korea \\ * Department of Mechanical Engineering, Hansung University, \\ Samsun-Dong, Sunghuk-Gu, Seoul 136-042, Korea
}

(Received June 16, 1998)

\begin{abstract}
The effects of isomeric oxydiphenylene diamines (ODA), 3,4'ODA and 4,4'ODA, on the water sorption behavior in pyromellitic dianhydride (PMDA)-ODA, biphenyltetracarboxylic dianhydride (BPDA)-ODA, 3,3',4,4'-benzo phenonetetracarboxylic dianhydride (BTDA)-ODA, and 4,4'-hexafluoroisopropylidenediphthalic anhydride (6FDA)-ODA polyimides were gravimetrically investigated. Water sorption curves were reasonably well fitted by Fickian diffusion despite their morphological heterogeneities in the polyimide thin films. However, the effects of isomeric ODA on the water sorption were quite different depending upon the sort of polyimide. The mutual diffusion coefficient of water and 4,4 'ODA based polyimide films varies in the range of $3.0 \times 10^{-10} \mathrm{~cm}^{2} \mathrm{~s}^{-1}$ to $15.2 \times 10^{-10} \mathrm{~cm}^{2} \mathrm{~s}^{-1}$, and is in the increasing order: BPDA-4, $4^{\prime}$ ODA $<$ BTDA-4, $4^{\prime}$ ODA-PMDA-4.4'ODA <6FDA-4, $4^{\prime}$ ODA. The water uptake varies from $1.62 \mathrm{wt} \%$ to 3.25 $\mathrm{wt} \%$, and is in the increasing order: BPDA-4,4'ODA $<6$ FDA $-4,4^{\prime}$ ODA $<$ PMDA $-4,4^{\prime}$ ODA $<$ BTDA-4, $4^{\prime}$ ODA. However, the diffusion coefficient for $3,4^{\prime}$ ODA based polyimide films varies in the range of $6.7 \times 10^{-10} \mathrm{~cm}^{2} \mathrm{~s}^{-1}$ to $8.6 \times 10^{-10} \mathrm{~cm}^{2} \mathrm{~s}^{-1}$, and is in the increasing order: BPDA-3,4'ODA $<6$ FDA-3,4'ODA-BTDA-3,4'ODA-PMDA-3,4'ODA. The water uptake varies from $2.02 \mathrm{wt} \%$ to $2.98 \mathrm{wt} \%$, and is in the increasing order: 6 FDA-3,4'ODA $<$ BPDA-3,4'ODA $<$ BTDA-3,4'ODA $<$ PMDA$3,4^{\prime}$ ODA. Polyimides having higher chain order, highly crystalline structure, and smaller mean intermolecular distance revealed relatively lower diffusion coefficients and water uptakes in equilibrium.
\end{abstract}

KEY WORDS Water Sorption/Morphological Structure / Chemical Affinity / Diffusion Coefficient Isomeric Oxydiphenylene Diamines

Polyimides have been used extensively in the microelectronics industry. A wide variety of applications includes interlayer dielectrics in integrated circuits, intermetal insulators in high density interconnect packaging, and thermal-mechanical passivation buffer protection layers. Polyimides have several advantages that make them attractive for microelectronics applications. ${ }^{1-4}$ They have a low dielectric permittivity, are an excellent planarizer and thermally stable up to $400^{\circ} \mathrm{C}$. Moreover, the driving forces in very large scale integration (VLSI) technology includes the use of polyimides for dry etching and low-temperature processing. Polyimides can be plasma etched and fully processed at temperatures of $400^{\circ} \mathrm{C}$ and below. ${ }^{2}$ Compared with conventional inorganic materials, polyimides have the advantage of being able to be applied by spin coating making them compatible with standard integrated circuit fabrication techniques. Polyimides offer improved stress relief. Such thin films on large substrates can be prepared without pinholes. The dielectric constant of polyimide is typically in the range of $3.0-4.0$, making it acceptable as a low capacitance dielectric between metallization levels. These combinations of characteristics make polyimides a promising replacement for the insulator in microelectronic devices. ${ }^{1-3}$

However, despite the relatively high chemical resistance characteristics, polyimides still absorb water, ${ }^{2,3}$ sometimes causing reliability problems in multi-layer module. Specially, the water sorptions of polyimide films not only cause the potential reliability problems, ${ }^{2-7}$ such as displacement, crack, delamination, loss of adhesion, potential corrosion, and mechanical failures in thin films, but may place processing constraints on device fabrication. As to retaining or improving the dielectric property, sorption of water in the imide films should be minimized. Upon sorption of water, the dielectric constants and conductivities in the polyimide films as well as the level of dielectric loss will increase. Therefore, it will be very helpful to understand the sorption behavior of water in polyimides and to minimize the total sorption of water because the final equilibrium water sorption provides an upper limit on the dielectric constant of the material. In addition, for the development of advanced materials, knowledge of environment effects on the behavior of high performance polyimide is essential for the design and selection of structural materials.

Water sorption and diffusion in the polyimide films have been widely studied by several research groups using various methods: quartz-spring microbalances, ${ }^{8,9}$ electromicrobalances, ${ }^{10-16}$ stress relaxation analyzers, ${ }^{14,17,18}$ capacitance methods, ${ }^{19}$ and infrared attenuated total reflectance (ATR) methods. ${ }^{20}$ Both poly $\left(4,4^{\prime}\right.$-oxydiphenylene pyromellitimide) (PMDA-4,4'ODA) and poly $(p$ phenylene biphenyltetracarboximide) (BPDA-PDA) films have been extensively investigated from the viewpoint of water sorption and diffusion. ${ }^{10-13}$ However, it is well known that the water sorptions in the polyimide films are probably dependent on the chemical backbone structure and the morphological structure, which originates in the processing history of curing. The goal

+ To whom correspondence should be addressed (Tel: +82-2-361-2764, Fax: +82-2-312-6401, e-mail: hshan ( $a$ bubble.yonsei.ac.kr). 
<smiles>Cc1ccc(Oc2ccc(-n3c(=O)c4cc5c(=O)n(C)c(=O)c5cc4c3=O)cc2)cc1</smiles><smiles>Cc1ccc(Oc2ccc(N3C(=O)c4ccc(-c5ccc6c(c5)C(=O)N(C)C6=O)cc4C3=O)cc2)cc1</smiles><smiles>Cc1ccc(Oc2ccc(N3C(=O)c4ccc(C(=O)c5ccc6c(c5)C(=O)N(C)C6O)cc4C3=O)cc2)cc1</smiles><smiles>COC(=O)O[Mg]</smiles><smiles>Cc1cccc(Oc2ccc(N3C(=O)c4cc5c(cc4C3=O)C(O)N(C)C5=O)cc2)c1</smiles><smiles>[R6]OC1c2ccc(-c3ccc4c(c3)C(=O)N(C)C4=O)cc2C(=O)N1c1ccc(Oc2cccc(C)c2)cc1</smiles><smiles>Cc1cccc(Oc2ccc(N3C(=O)c4ccc(C(=O)c5ccc6c(c5)C(=O)N(C)C6=O)cc4C3=O)cc2)c1</smiles>

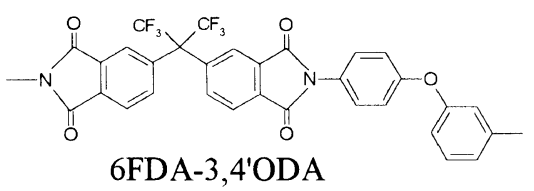

Figure 1. Chemical structures of polyimides.

of this work is to investigate the relationship between the chemical structure and the morphological structure with the water sorption behavior in the polyimide thin films. In the present study, the water sorption kinetics in the polyimide thin films based on two isomeric oxydiphenylene diamines, 4,4'-oxydiphenylene diamine (4,4'ODA) and $3,4^{\prime}$-oxydiphenylene diamine (3, $\left.4^{\prime} \mathrm{ODA}\right)$, were gravimetrically investigated in detail by using a modified electromicrobalance (Thin Film Diffusion Analyzer). The water sorption behavior in the polyimide films was interpreted with the consideration of the chemical structure and the morphological structure.

\section{EXPERIMENTAL}

\section{Materials and Sample Preparation}

All the chemical structures of polyimides are shown in Figure 1. Diamine and dianhydride monomers were purchased from commercial products: pyromellitic dianhydride (PMDA), biphenyltetracarboxylic dianhydride (BPDA), 3,3',4,4'-benzo phenonetetracarboxylic dianhydride (BTDA), 4,4'-hexafluoroisopropylidenediphthalic anhydride (6FDA), and isomeric diamines: 4, $4^{\prime}$-oxydiphenylene diamine (4,4'ODA) and 3,4'-oxydiphenylene diamine $\left(3,4^{\prime} \mathrm{ODA}\right)$. All the monomers were purified by sublimation under reduced pressure or recrystallization. All the polymerizations as shown in Figure 2 were conducted in previously described methods. ${ }^{1-3}$ The precursor solutions had a solid content of $15 \mathrm{wt} \%$.

All the polyimide precursors were spin coated on silicon $(100)$ substrates. Coated wafers were prebaked at $80^{\circ} \mathrm{C}$ for $30 \mathrm{~min}$ on the hot plate under nitrogen flow. The prebaked precursors on silicon substrates were then placed in the curing oven and cured under flowing nitrogen by the following cure schedule: ${ }^{10-14} 150^{\circ} \mathrm{C} / 30$ $\min , 230^{\circ} \mathrm{C} / 30 \mathrm{~min}, 300^{\circ} \mathrm{C} / 30 \mathrm{~min}$, and $400^{\circ} \mathrm{C} / 60 \mathrm{~min}$.
The ramping rate was $2.5^{\circ} \mathrm{C} \mathrm{min}^{-1}$ and the cooling rate was $2.0^{\circ} \mathrm{C} \mathrm{min}^{-1}$ for the curing process. The thickness of the polyimide thin films was controlled in the range of $10-14$ microns by spinning speed to minimize the effect of thickness. ${ }^{10-13}$ Here, the film thickness was measured using a Tencor Surface Profiler (Model P-10). The films were then taken off from the substrates with the aid of deionized water and were then washed with distilled water several times and dried. The fully cured films were cut into rectangular pieces approximately $10 \mathrm{~mm} \times 15 \mathrm{~mm}$ and fully dried in a vacuum prior to use for the gravimetric measurement and X-ray diffraction measurements.

\section{Measurements}

For the fully cured polyimide films, water sorptions were measured at $100 \%$ relative humidity (R.H.) and $25^{\circ} \mathrm{C}$ as a function of time by using a Thin Film Diffusion Analyzer (Cahn Instruments, Model D-200) with the resolution of $0.1 \mu \mathrm{g}$ over $20 \mathrm{mg}$ weight loading as described in previous studies. ${ }^{10-14}$ All the sorption curves were analyzed with Fick's second law, which has been driven for an infinite slab with a constant surface concentration: ${ }^{21,22}$

$$
\begin{gathered}
M(t) \\
M(\infty)
\end{gathered}=1-\frac{8}{\pi^{2}} \sum_{m=0}^{\infty} \frac{1}{(2 m+1)^{2}} \exp \left(\begin{array}{c}
-D(2 m+1)^{2} \pi^{2} t \\
L^{2}
\end{array}\right)
$$

where $M(t)$ is the water sorption at a time $t, M(\infty)$ is the water sorption at $t=\infty, D$ is the mutual diffusion coefficient of water and polymer systems, and $L$ is the film thickness. The experimental data of the entire experimental range were fitted with eq 1 , leading to the estimation of the mutual diffusion coefficient.

Wide-angle X-ray diffraction (WAXD) patterns were 


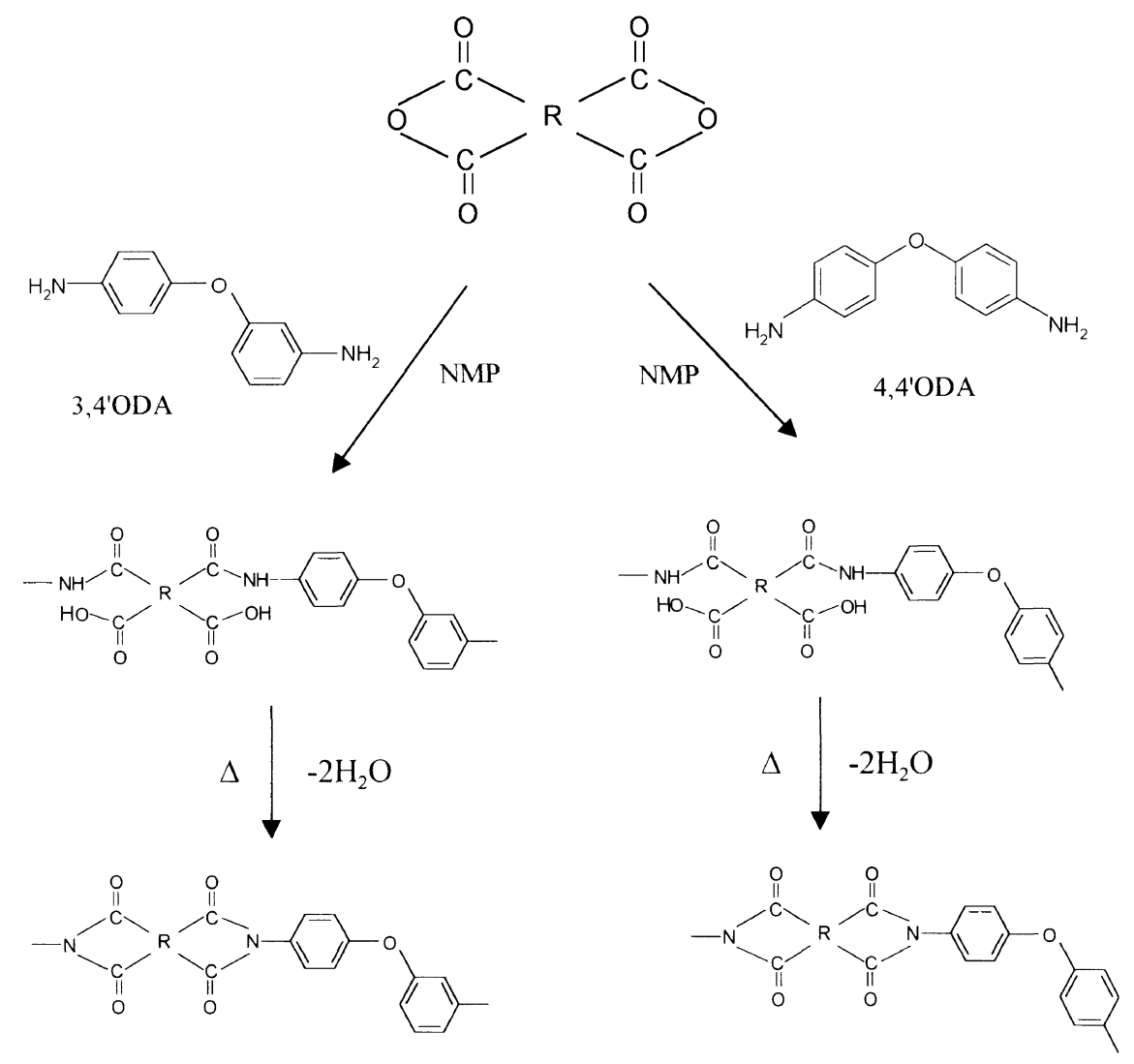

Figure 2. Schematic diagram of the synthesis from dianhydrides and two isomeric oxydiphenylene diamines, 4,4'ODA and $3,4^{\prime}$ ODA.

corrected from the polyimide thin film specimens on a Rigaku horizontal X-ray diffraction apparatus with nickel-filtered radiation. One diffractometer was setup for measurements in the transmission mode (i.e., reflections from lattice planes normal to the film surface) with a thin asymmetric cut (101) quartz plate monochromator bent to a section of a logarithmic spiral and located in the diffracted beam. The other was used for measurements in the reflection mode (i.e., reflections from lattice planes parallel to the film surface) with a curved graphite monochromator in the diffracted beam. The $\mathrm{Cu}-K_{\alpha}$ radiation source $(\lambda=1.54 \AA)$ was operated at $35 \mathrm{kV}$ and $40 \mathrm{~mA}$ and all measurements were carried out $\theta / 2 \theta$ mode. The $2 \theta$ scan data were collected in the range of $5-60^{\circ}$ at $0.02^{\circ}$ intervals with a scan speed of $0.3-0.5^{\circ} \mathrm{min}^{-1}$, depending upon whether a reflection or transmission scan was being made.

\section{RESULTS AND DISCUSSION}

\section{Water Sorption}

The water sorptions for the thermally imidized polyimide films based on two ODA isomeric diamines, $4,4^{\prime} \mathrm{ODA}$ and 3,4'ODA, were measured at $100 \%$ R.H. and $25^{\circ} \mathrm{C}$. Polyimide films had approximately the same thickness in the range of $10-14 \mu \mathrm{m} . .^{10-14}$ Typical curves of the water sorption for all the polyimides with 4,4'ODA and 3,4'ODA diamines are shown in Figures 3 and 4, respectively. The sorption curves of all the polyimide films were reasonably well fitted by Fick's second law despite the morphological heterogeneities ${ }^{23-25}$ due to the ordered and disordered phases in polymer thin films. However, there exists a small inflection in the data at

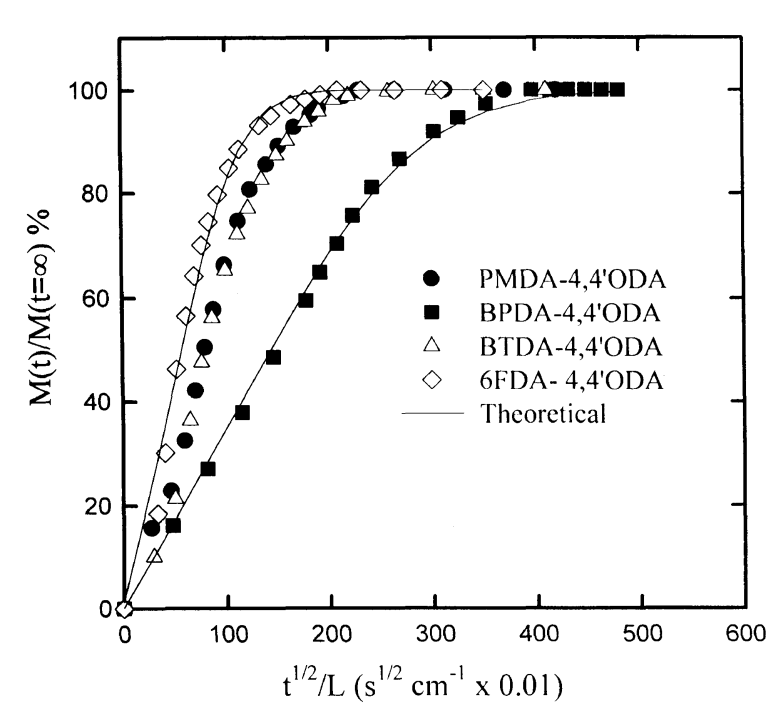

Figure 3. Curves of water sorption in the polyimide thin films with $4,4^{\prime}$ ODA diamine at $100 \%$ R.H. and $25^{\circ} \mathrm{C}$.

short times, which might be resulted from the experimental start-up transient at the induction time.

However, the water sorptions of the polyimide thin films are quite different from each other and strongly dependent upon the sort of polyimide, and summarized in Table I. The diffusion coefficient of water and 4,4'ODA based polyimide films varies in the range of $3.0 \times 10^{-10}$ $\mathrm{cm}^{2} \mathrm{~s}^{-1}$ to $15.2 \times 10^{-10} \mathrm{~cm}^{2} \mathrm{~s}^{-1}$, and is in the increasing order: BPDA-4,4'ODA < BTDA-4,4'ODA-PMDA$4,4^{\prime}$ ODA $<6$ FDA-4,4'ODA. The water uptake varies from $1.62 \mathrm{wt} \%$ to $3.25 \mathrm{wt} \%$, and is in the increasing order: BPDA-4, 4'ODA $<6$ FDA-4,4'ODA $<$ PMDA- 


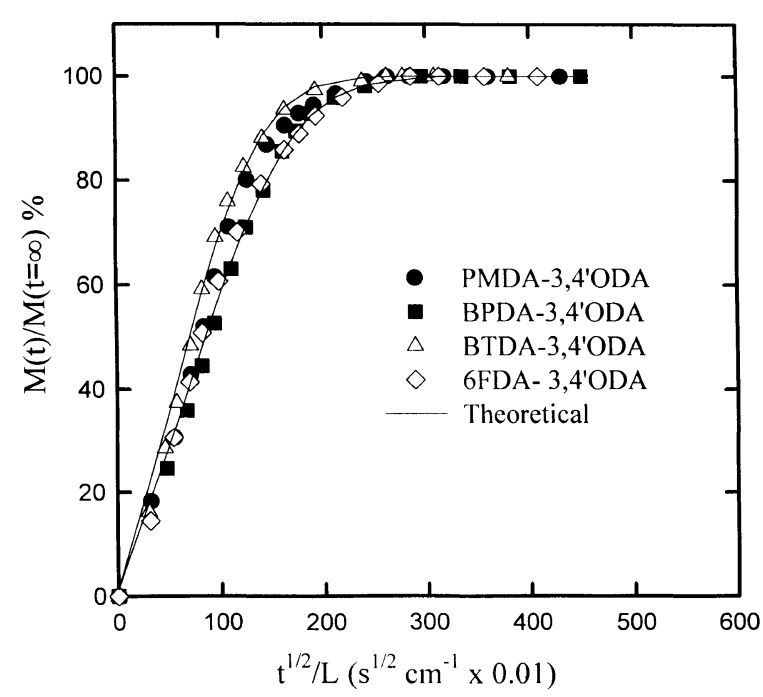

Figure 4. Curves of water sorption in the polyimide thin films with $3,4^{\prime}$ ODA diamine at $100 \%$ R.H. and $25^{\circ} \mathrm{C}$.

Table I. Diffusion coefficients and water uptakes for the polyimide thin films based on two isomeric oxydiphenylene diamines, $3,4^{\prime}$ ODA and $4,4^{\prime} \mathrm{ODA}$

\begin{tabular}{|c|c|c|c|}
\hline \multirow[t]{2}{*}{ Polymer } & $\begin{array}{l}\text { Film } \\
\text { thickness }\end{array}$ & $\begin{array}{l}\text { Diffusion } \\
\text { coefficient } \\
D \times 10^{-10}\end{array}$ & $\begin{array}{l}\text { Water } \\
\text { uptake }\end{array}$ \\
\hline & $\mu \mathrm{m}$ & $\mathrm{cm}^{2} \mathrm{~s}^{-1}$ & $\mathrm{wt} \%$ \\
\hline PMDA-4,4'ODA & 11.97 & 9.4 & 3.06 \\
\hline PMDA-3,4'ODA & 12.20 & 8.6 & 2.98 \\
\hline BPDA-4,4'ODA & 12.80 & 3.0 & 1.62 \\
\hline BPDA-3,4'ODA & 10.94 & 6.7 & 2.32 \\
\hline BTDA- $4,4^{\prime}$ ODA & 10.98 & 9.0 & 3.25 \\
\hline BTDA-3,4'ODA & 12.98 & 8.3 & 2.86 \\
\hline $6 \mathrm{FDA}-4,4^{\prime} \mathrm{ODA}$ & 13.63 & 15.2 & 2.42 \\
\hline $6 \mathrm{FDA}-3,4^{\prime} \mathrm{ODA}$ & 10.10 & 8.2 & 2.02 \\
\hline
\end{tabular}

4,4'ODA < BTDA-4,4'ODA. The diffusion coefficient for $3,4^{\prime}$ ODA based polyimide films varies in the range of $6.7 \times 10^{-10} \mathrm{~cm}^{2} \mathrm{~s}^{-1}$ to $8.6 \times 10^{-10} \mathrm{~cm}^{2} \mathrm{~s}^{-1}$, and is in the increasing order: BPDA-3, $4^{\prime} \mathrm{ODA}<6 \mathrm{FDA}-3,4^{\prime} \mathrm{ODA}-$ BTDA-3,4'ODA-PMDA-3,4'ODA. The water uptake varies from $2.02 \mathrm{wt} \%$ to $2.98 \mathrm{wt} \%$, and is in the increasing order: 6FDA-3, 4'ODA $<$ BPDA-3, $4^{\prime}$ ODA $<$ BTDA$3,4^{\prime}$ ODA $<$ PMDA-3, $4^{\prime}$ ODA. As shown in Figures 3 and 4 , there exists relatively large difference in the curves of the water sorption for the $4,4^{\prime}$ ODA based polyimides with different dianhydrides, which is not preserved for those of the corresponding 3,4'ODA based polyimides.

Also, to elucidate the effects of isomeric diamines on the water sorption in the polyimide films, the water sorption curves are depicted in Figures 5, 6, 7, and 8. Figure 5 shows the water sorption curves of the PMDA based isomeric polyimide thin films; PMDA-4,4'ODA and PMDA-3,4'ODA. From the best fittings of the curves by eq 1 , the diffusion coefficients and water uptakes in equilibrium were estimated to be $9.4 \times 10^{-10} \mathrm{~cm}^{2} \mathrm{~s}^{-1}$ and $3.06 \mathrm{wt} \%$ for PMDA-4,4'ODA and $8.6 \times 10^{-10} \mathrm{~cm}^{2} \mathrm{~s}^{-1}$ and $2.98 \mathrm{wt} \%$ for PMDA-3,4'ODA, respectively. These

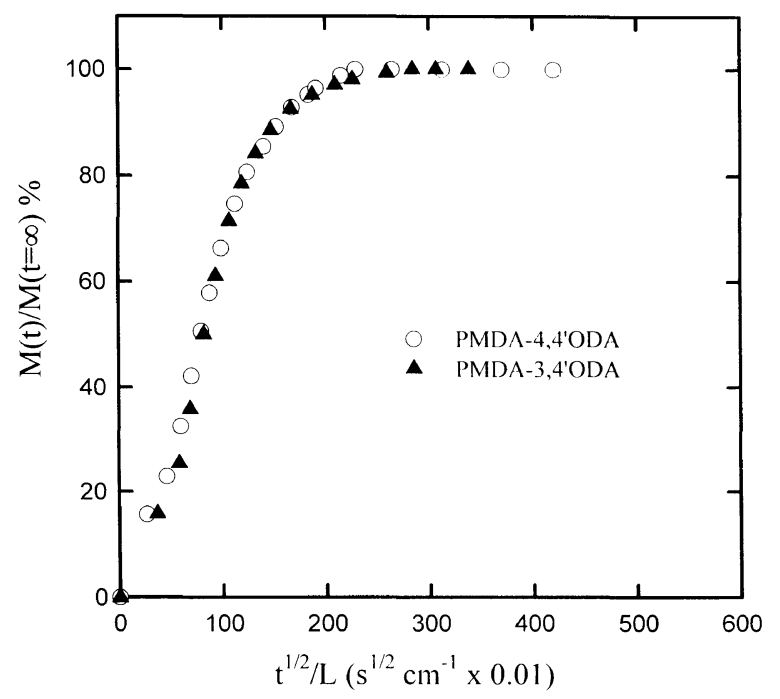

Figure 5. Curves of water sorption in PMDA-4,4'ODA and PMDA$3,4^{\prime}$ ODA polyimide thin films at $100 \%$ R.H. and $25^{\circ} \mathrm{C}$.

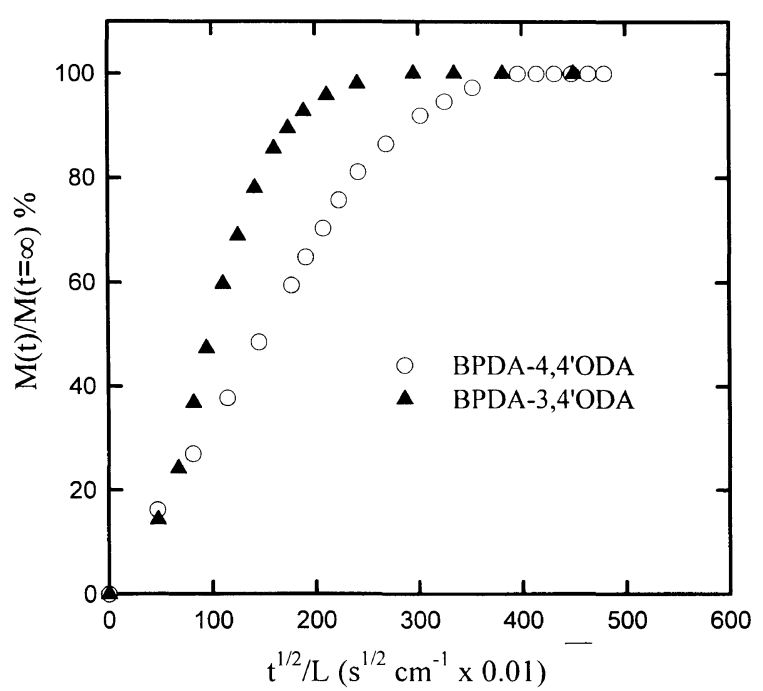

Figure 6. Curves of water sorption in BPDA-4,4'ODA and BPDA$3,4^{\prime}$ ODA polyimide thin films at $100 \%$ R.H. and $25^{\circ} \mathrm{C}$.

results indicate that water was a little quickly and more diffused into film of PMDA-4,4'ODA than that of PMDA-3,4'ODA. There were no significant differences in the diffusion coefficient and the water uptake.

For the BPDA based isomeric polyimide thin films, BPDA-4,4'ODA exhibited diffusion coefficient of $3.0 \times$ $10^{-10} \mathrm{~cm}^{2} \mathrm{~s}^{-1}$ and $1.62 \mathrm{wt} \%$ water uptake. The corresponding BPDA-3, $4^{\prime}$ ODA revealed diffusion coefficient of $6.7 \times 10^{-10} \mathrm{~cm}^{2} \mathrm{~s}^{-1}$ and $2.32 \mathrm{wt} \%$ water uptake. In comparison of the PMDA based polyimides, there exists relatively larger difference in the water sorption kinetics of two the BPDA based isomeric polyimides. However, the larger amount of water was sorbed more quickly into BPDA-3,4'ODA than BPDA-4,4'ODA.

Similar behavior with the sorption curves of the PMDA based polyimides was observed in that of BTDA based isomeric polyimide films. For the BTDA based polyimide thin films, BTDA-4,4'ODA exhibited diffusion coefficient of $9.0 \times 10^{-10} \mathrm{~cm}^{2} \mathrm{~s}^{-1}$ and $3.25 \mathrm{wt} \%$ water uptake. The corresponding BTDA-3,4'ODA revealed diffusion coefficient of $8.3 \times 10^{-10} \mathrm{~cm}^{2} \mathrm{~s}^{-1}$ and $2.86 \mathrm{wt} \%$ water uptake. However, there exist no significant dif- 


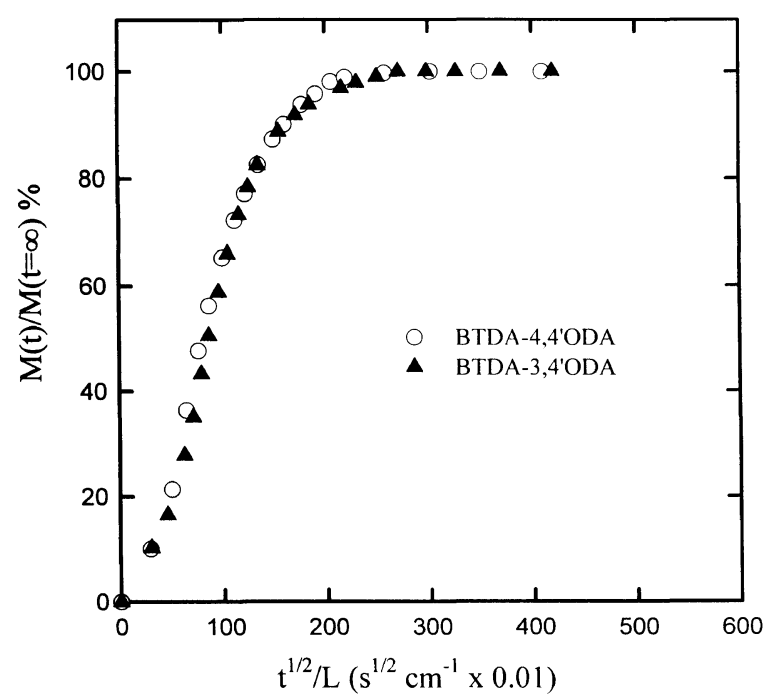

Figure 7. Curves of water sorption in BTDA-4,4'ODA and BTDA$3,4^{\prime} \mathrm{ODA}$ polyimide thin films at $100 \%$ R.H. and $25^{\circ} \mathrm{C}$.

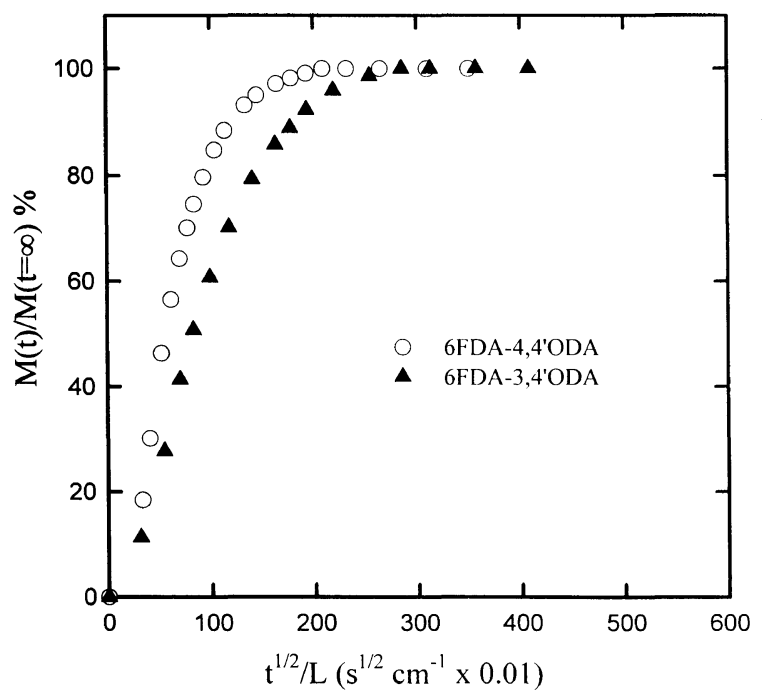

Figure 8. Curves of water sorption in 6FDA-4,4'ODA and 6FDA$3,4^{\prime}$ ODA polyimide thin films at $100 \%$ R.H. and $25^{\circ} \mathrm{C}$.

ferences in the diffusion coefficient and the water uptake as shown in Figure 7.

For the 6FDA based isomeric polyimide thin films, 6FDA-4,4'ODA exhibited diffusion coefficient of $15.2 \times$ $10^{-10} \mathrm{~cm}^{2} \mathrm{~s}^{-1}$ and $2.42 \mathrm{wt} \%$ water uptake. The corresponding 6FDA-3,4'ODA revealed diffusion coefficient of $8.2 \times 10^{-10} \mathrm{~cm}^{2} \mathrm{~s}^{-1}$ and $2.02 \mathrm{wt} \%$ water uptake. That is, the larger amount of water was more quickly diffused into the film of 6 FDA-4,4'ODA than was that of 6FDA$3,4^{\prime} \mathrm{ODA}$.

As shown in Table I and Figures 5, 6, 7, and 8, the polyimide films based on 4,4'ODA diamine, though except of BPDA, showed relatively higher diffusion coefficients of water than those based 3,4'ODA diamine. Also, the amounts of water absorbed in the films were consistent with the diffusion coefficients for the polyimide films. For the BPDA based polyimides, however, that with 4,4'ODA showed lower diffusion coefficient and uptake than that with $3,4^{\prime}$ ODA.

The water sorption in the polyimide films with two ODA isomeric diamines can be interpreted by consider- ing two major contributory factors, morphological structure and chemical affinity to water. For some of the polyimides, Han and Ree et al. ${ }^{10,11}$ obtained experimentally the chemical affinity to water by measuring the surface energy. Other several researchers ${ }^{2,8,26,27}$ calculated the solubility parameter, $\delta$, which means the mutual solubility, by the group contribution method of van Krevelen. ${ }^{27}$ Hydrogen bonding and polar groups affect with the solubility as well, because molecules dissolve preferentially in hosts with similar degrees of hydrogen bonding. Regarding the chemical backbones, the chemical affinity of two isomeric diamine monomeric units to water is the same. However, from the chemical structure of dianhydride and the previous other studies, ${ }^{2,10,12,26,27}$ the chemical affinity of dianhydride monomeric units to water is in the increasing order: 6 FDA $<$ BPDA $<$ PMDA $<$ BTDA. It can be simply expected that the water sorption in the film is in the increasing order: $6 \mathrm{FDA}$ based polyimide $<$ BPDA based polyimide $<$ PMDA based polyimide $<$ BTDA based polyimide. However, this prediction is not in good agreement with water sorption. From these deviated results, it is suggested that in addition to the chemical affinity to water, the morphological structure term, which includes chain order, crystallinity, packing, and interchain spacing, may play an important role in the water sorption behavior.

\section{Morphological Structure}

To relate the morphological structure with the water sorption behavior, WAXD measurements were performed for the fully imidized polyimide films at $400^{\circ} \mathrm{C}$. The transmission patterns give the structural information in the film plane, whereas the reflection patterns give structural information in the out-of-film plane..$^{10-14}$ WAXD results are depicted in Figures 9, 10, 11, and 12.

Generally, it is well known that the greater interchain spacing, the more water uptake and the higher diffusion coefficient in films. Smaller interchain spacing usually means a stronger interchain molecular interaction. In addition to the chain order and the crystallinity of films resulted from the difference of the chemical structure, the distance of the interchain spacing might be critical factor to the water sorption in films. ${ }^{12,17}$ To investigate the relationship between the water sorption and the chain spacing of chain, the mean intermolecular distances in thin films of polyimides were calculated from the peak maximum according to the Bragg's equation, ${ }^{28}$ from the peak maximum of amorphous halos in the transmission and reflection WAXD patterns, respectively. These results are summarized in Table II.

For the PMDA based isomeric polyimide films, PMDA-4,4'ODA and PMDA-3,4'ODA, the reflection and transmission patterns were shown in Figure 9. It indicates that PMDA-3,4'ODA exhibits a well-developed crystalline structure, whereas PMDA-4,4'ODA does not. According to X-ray diffraction patterns, PMDA$3,4^{\prime}$ ODA polyimide exhibits a highly ordered molecular orientation and lateral packing. On the other hand, PMDA-4,4'ODA shows only a molecular orientation along the chain axis, without any good lateral packing. It suggests that PMDA-3,4'ODA having well developed crystalline structure and relatively high lateral packing 
Table II. Mean intermolecular distances in the polyimide thin films based on two isomeric oxydiphenylene diamines, 3,4'ODA and 4,4'ODA

\begin{tabular}{|c|c|c|c|}
\hline \multirow{2}{*}{ Polymer } & \multirow{2}{*}{$\frac{\begin{array}{c}\text { Film } \\
\text { thickness }\end{array}}{\mu \mathrm{m}}$} & \multicolumn{2}{|c|}{ Mean intermolecular distance ${ }^{\mathbf{a}}$} \\
\hline & & In-plane ${ }^{b}$ & Out-of-plane ${ }^{c}$ \\
\hline PMDA-4,4'ODA & 11.97 & $0.494 \mathrm{~nm}\left(18.18^{\circ}\right)$ & $0.488 \mathrm{~nm}\left(18.42^{\circ}\right)$ \\
\hline PMDA-3,4'ODA & 12.20 & $0.441 \mathrm{~nm}\left(20.40^{\circ}\right)$ & $0.474 \mathrm{~nm}\left(18.98^{\circ}\right)$ \\
\hline BPDA-4.4'ODA & 12.80 & $0.466 \mathrm{~nm}\left(19.32^{\circ}\right)$ & $0.479 \mathrm{~nm}\left(18.76^{\circ}\right)$ \\
\hline BPDA-3,4'ODA & 10.94 & $0.514 \mathrm{~nm}\left(17.46^{\circ}\right)$ & $0.501 \mathrm{~nm}\left(17.92^{\circ}\right)$ \\
\hline BTDA-4,4'ODA & 10.98 & $0.523 \mathrm{~nm}\left(17.16^{\circ}\right)$ & $0.488 \mathrm{~nm}\left(18.42^{\circ}\right)$ \\
\hline BTDA-3,4'ODA & 12.98 & $0.465 \mathrm{~nm}\left(19.38^{\circ}\right)$ & $0.460 \mathrm{~nm}\left(19.60^{\circ}\right)$ \\
\hline $6 \mathrm{FDA}-4,4^{\prime} \mathrm{ODA}$ & 13.63 & $0.573 \mathrm{~nm}\left(15.60^{\circ}\right)$ & $0.561 \mathrm{~nm}\left(15.96^{\circ}\right)$ \\
\hline 6FDA-3,4'ODA & 10.10 & $0.566 \mathrm{~nm}\left(15.80^{\circ}\right)$ & $0.582 \mathrm{~nm}\left(15.36^{\circ}\right)$ \\
\hline
\end{tabular}

a Calculated from the peak maximum according to the Bragg's equation. ${ }^{\mathrm{b}}$ Calculated from the peak maximum of amorphous halos in the transmission WAXD patterns. ${ }^{\mathrm{c}}$ Calculated from the peak maximum of amorphous halos in the reflection WAXD patterns.

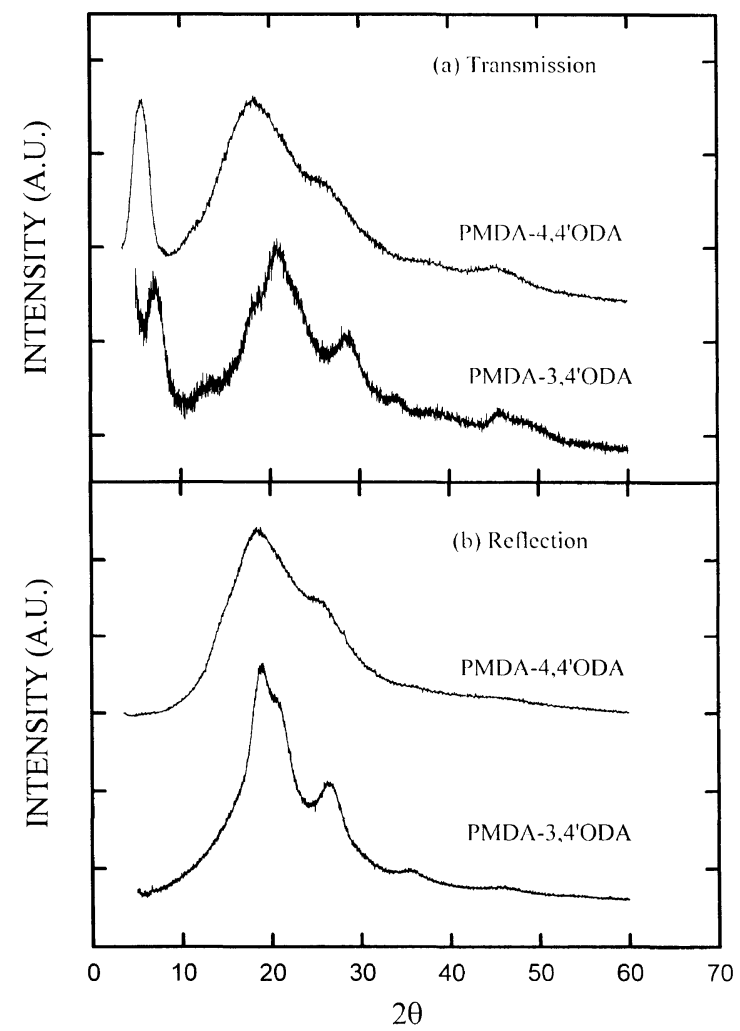

Figure 9. WAXD intensity profiles of PMDA-4,4'ODA and PMDA$3,4^{\prime}$ ODA polyimides in (a) transmission and (b) reflection patterns.

show relatively lower diffusion coefficient and lower water uptake in equilibrium than PMDA-4,4'ODA having lower degree of chain order and crystallinity. In comparison of the mean intermolecular distance and the water sorption, PMDA-4,4'ODA having relatively greater mean intermolecular distance showed relatively higher diffusion coefficient and uptake than PMDA$3,4^{\prime}$ ODA. However, water sorption behavior is not so different. These may be attributed to the morphological defects on the water sorption in PMDA-3,4'ODA by the insufficient mobilities of chains having a high glass

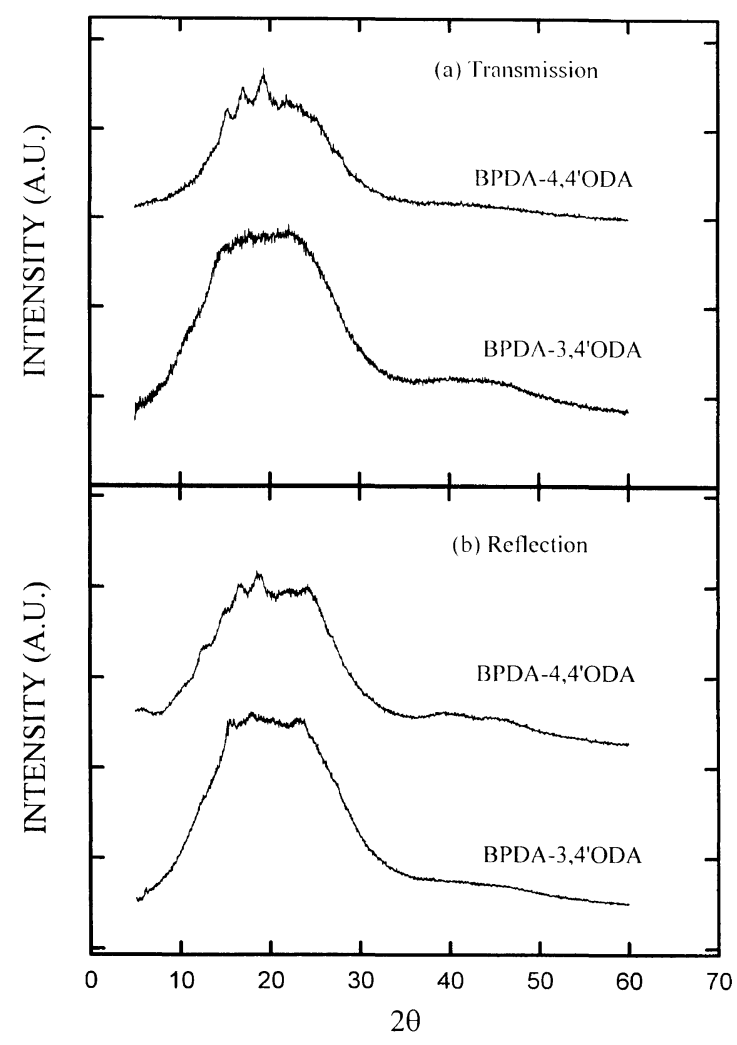

Figure 10. WAXD intensity profiles of BPDA-4,4'ODA and BPDA$3,4^{\prime}$ ODA polyimides in (a) transmission and (b) reflection patterns.

transition temperature. ${ }^{12,14}$

For the BPDA based isomeric polyimides, BPDA$4,4^{\prime}$ ODA and BPDA-3,4'ODA, the diffraction patterns are shown in Figure 10. BPDA-4,4'ODA showed multiple diffraction peaks seated on the big amorphous halo peak in the diffraction patterns over the angle range of 10 to $30^{\circ}(2 \theta)$ for both the transmission and reflection patterns. However, unlike BPDA-4,4'ODA, BPDA-3,4'ODA revealed only big amorphous halos in both the transmission and reflection patterns. These diffraction patterns indicate that BPDA-4,4'ODA polyimide exhibits a welldeveloped crystalline structure, whereas BPDA-3,4'ODA does not. Conclusively, BPDA-4,4'ODA have a highly crystalline structure for in the film plane and in the outof-plane, and whereas BPDA-3,4'ODA does not. BPDA$4,4^{\prime}$ ODA having relatively highly crystalline structure revealed apparently lower diffusion coefficient and water uptake than BPDA-3,4'ODA having amorphous structure. Unlike PMDA-ODA, BPDA-4,4'ODA showed a relatively shorter mean intermolecular distance than BPDA-3,4'ODA for the transmission and reflection patterns, as shown in Table II. WAXD results were well consistent with those of water sorption in the BPDA based polyimides as shown in Figure 4.

Both BTDA-4,4'ODA and BTDA-3,4'ODA revealed no characteristic peaks, but only one amorphous halos in both transmission and reflection patterns, as shown in Figure 11. These WAXD results indicate that both the BTDA based polyimides exhibit amorphous structures which give favorable sites to the water sorption. However, BTDA-3,4'ODA showed a relatively shorter mean intermolecular distance than BTDA-4,4'ODA for the transmission and reflection patterns, as shown in 


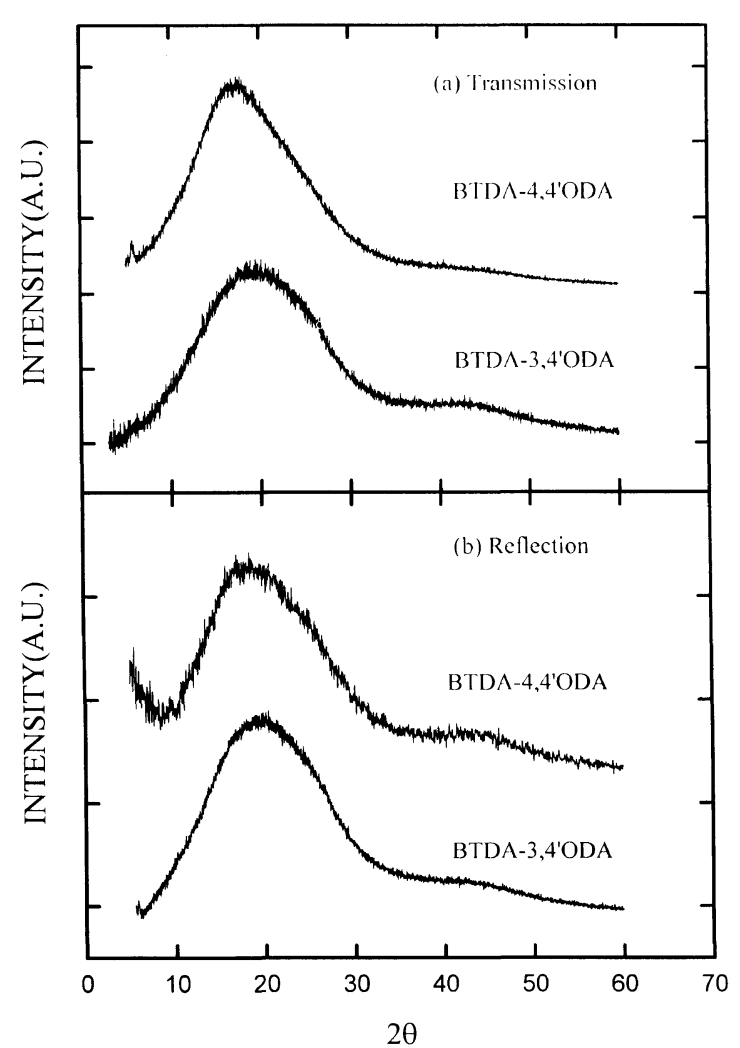

Figure 11. WAXD intensity profiles of BTDA-4,4'ODA and BTDA$3,4^{\prime}$ ODA polyimides in (a) transmission and (b) reflection patterns.

Table II. In comparison of the mean intermolecular distance and the water sorption in the BTDA based polyimide films, BTDA-4,4'ODA having a relatively greater mean intermolecular distance showed relatively higher diffusion coefficient and water uptake than PMDA-4,4'ODA. It showed good agreements with the results of the water sorption in PMDA-ODA and BPDA-ODA polyimides. However, in contrast to the BPDA based polyimides, there exists no apparent difference in morphological structure. It shows a good consistency with the results of the water sorption as shown in Figure 5.

For the 6FDA based isomeric polyimides, 6FDA$4,4^{\prime}$ ODA and 6FDA-3,4'ODA, the diffraction patterns are depicted in Figure 12. Like the BTDA based polyimides, two polyimides exhibited no characteristic peaks, but only one amorphous halos in both the transmission and reflection patterns. It suggests that both 6FDA$4,4^{\prime} \mathrm{ODA}$ and 6FDA-3,4'ODA are structureless and amorphous. In addition, the chain order and the inplane orientation of chains in the polyimide films did not exist. These might result from the very poor packing of polymer chains due to the weak molecular interaction and the steric hindrance caused by $-\mathrm{C}\left(\mathrm{CF}_{3}\right)_{2}$ groups. However, 6FDA-4,4'ODA showed relatively higher diffusion coefficient and larger water uptake than did 6FDA-3,4'ODA.

In general, their ability to form the ordered and crystalline structures depends on the nature of the swivel groups and on the way the samples were prepared. ${ }^{1,2}$ In present study, as all the polyimides are prepared by using the same curing process, the degrees of chain order in polyimide are solely dependent upon on the chemical

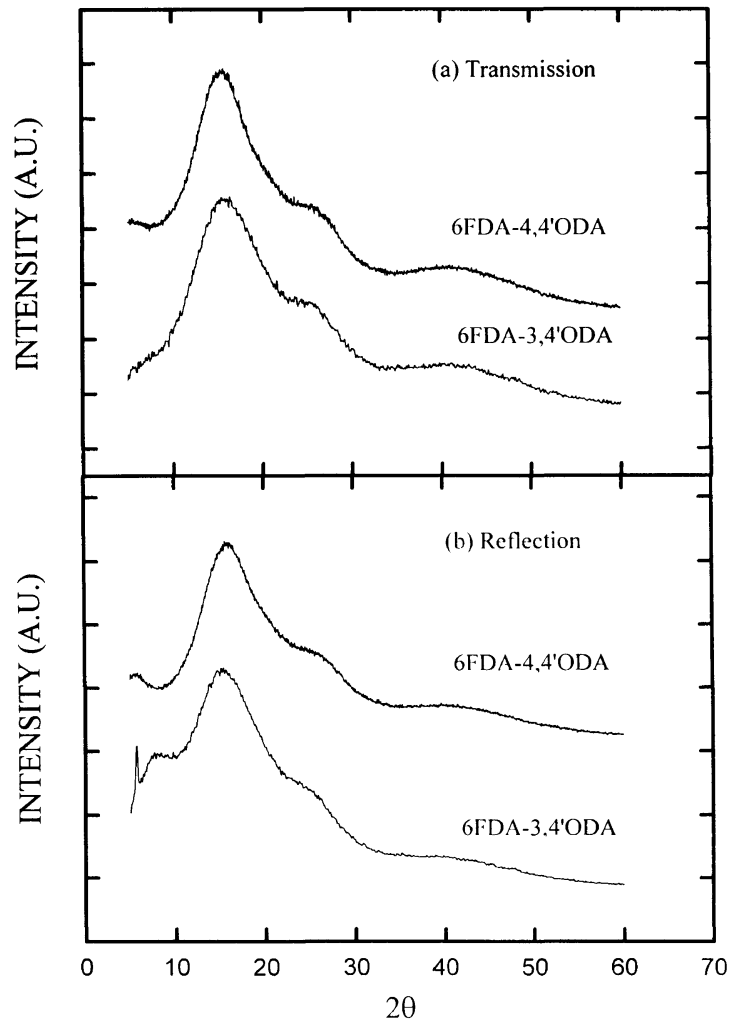

Figure 12. WAXD intensity profiles of 6FDA-4,4'ODA and 6FDA$3,4^{\prime}$ ODA polyimides in (a) transmission and (b) reflection patterns.

structure. Chains formed by two isomeric diamines, $4,4^{\prime} \mathrm{ODA}$ and 3,4'ODA, were kinked to some degree as shown in Figure 1. Polyimides based on 3,4'ODA diamine have two segments per repeat unit, if we model the polymer as a series of rigid line segments. Polyimides based on 4,4'ODA diamine has only one bend per repeat unit. It suggests that polyimides based on 4,4'ODA diamine packs in a more irregular fashion. This was in good agreement with the results of the water sorption. That is, polyimides based on $4,4^{\prime}$ ODA diamine revealed a relatively higher diffusion coefficient and higher water uptake than did their corresponding polyimides based on $3,4^{\prime}$ ODA. However, some exceptions exist in the BPDA based polyimide thin films.

In conclusion, both the chemical structure and the morphological structure are important parameters to control the mutual diffusion coefficient and water uptake in equilibrium. However, the morphological structures are more critical than the chemical structures in controlling it.

\section{CONCLUSIONS}

Polyimide thin films with two isomeric oxydiphenylene diamines, 4,4'ODA and 3,4'ODA, were prepared from their respective poly(amic acid) precursors by the thermal imidization at $400^{\circ} \mathrm{C}$. Sorption kinetics of water was gravimetrically studied by using a Thin Film Diffusion Analyzer. Water sorption curves in the polyimide thin films were reasonably well fitted by Fick's law despite their morphological heterogeneities. The water sorption curves are quite different depending upon the structure of polyimide. The mutual diffusion coefficient of water 
and $4,4^{\prime}$ ODA based polyimide films varies in the range of $3.0 \times 10^{-10} \mathrm{~cm}^{2} \mathrm{~s}^{-1}$ to $15.2 \times 10^{-10} \mathrm{~cm}^{2} \mathrm{~s}^{-1}$, and is in the increasing order: BPDA-4,4'ODA $<$ BTDA$4,4^{\prime}$ ODA-PMDA-4, $4^{\prime}$ ODA $<6$ FDA $-4,4^{\prime}$ ODA. The water uptake varies from $1.62 \mathrm{wt} \%$ to $3.25 \mathrm{wt} \%$, and is in the increasing order: BPDA-4,4'ODA $<6$ FDA4,4'ODA < PMDA-4,4'ODA < BTDA-4,4'ODA. However, the diffusion coefficient for $3,4^{\prime}$ ODA based polyimide films varies in the range of $6.7 \times 10^{-10} \mathrm{~cm}^{2} \mathrm{~s}^{-1}$ to $8.6 \times 10^{-10} \mathrm{~cm}^{2} \mathrm{~s}^{-1}$, and is in the increasing order: BPDA-3,4'ODA <6FDA-3, 4'ODA - BTDA-3,4'ODAPMDA-3,4'ODA. The water uptake varies from 2.02 $\mathrm{wt} \%$ to $2.98 \mathrm{wt} \%$, and is in the increasing order: 6FDA-3, 4'ODA < BPDA-3, 4' ODA < BTDA-3, $4^{\prime}$ ODA $<$ PMDA-3,4'ODA. It means that the morphological structure shows relatively more predominant factors on the water sorption kinetics of the polyimide thin films than does the chemical affinities. In addition, polyimide thin films having higher chain order, highly crystalline structure, and smaller mean intermolecular distance revealed relatively lower mutual diffusion coefficient and water uptake in equilibrium.

Acknowledgment. We would like to thank IITA (Institute of Information Technology Assessment, U96141 ) and KOSEF (Korea Science and Engineering Foundation, 971-1102-007-2) for financial support of this work.

\section{REFERENCES}

1. M. I. Bessonov and V. A. Zubkov, "Polyamic Acids and Polyimides; Synthesis, Transformations, and Structure," CRC Press, Boca Raton, FL, 1993.

2. M. K. Ghosh and K. L. Mittal, "Polyimides; Fundamentals and Applications," Marcel Dekker, Inc., New York, N.Y., 1996.

3. K. L. Mittal, "Polyimide; Synthesis, Characterization, and Applications," Plenum Press, New York, N.Y., 1984.

4. L. F. Thompson, C. G. Willson, and S. Tagawa, "Polymers for Microelectronics: Resists and Dielectrics," ACS Symposium Series No. 537, Washington, D.C., 1994.
5. F. Bellucci, I. Khamis, S. D. Senturia, and R. M. Latanision, $J$. Electrochem. Soc., 137, 1778 (1990).

6. J. Melcher, Y. Daben, and G. Arlt, IEEE Trans. on Elect. Ins., 24, 31 (1989).

7. D. D. Denton, D. R. Day, D. F. Priore, and S. D. Senturis, $J$. Elect. Mater., 14, 119 (1985).

8. K.-I. Okamoto, N. Tanihara, H. Watanabe, K. Tanaka, H. Kita, A. Nakamura, Y. Kusuki, and K. Nakagawa, J. Polym. Sci., Polym. Phys., 30, 1223 (1992).

9. L. R. Iler, C. Laundon, and W. J. Koros, J. Appl. Polym. Sci., 27, 1163 (1982).

10. M. Ree, H. Han, and C. C. Gryte, High Perform. Polym., 6, 321 (1994).

11. H. Han, C. C. Gryte, and M. Ree, Polymer, 36, 1663 (1995).

12. H. Han, J. Seo, M. Ree, S. M. Pyo, and C. C. Gryte, Polymer, 39, 2963 (1998).

13. M. Ree, H. Han, and C. C. Gryte, J. Polym. Sci., Polym. Phys. 33, 505 (1995).

14. J. Seo, H. Han, S. Kim, H. Chung, and Y. Joe, Polym. J., 31, 127 (1999).

15. B. S. Lim, A. S. Nowick, K. W. Lee, and A. Viehbeck, J. Polym. Sci., Polym. Phys., 31, 545 (1993).

16. H. Pranjoto and D. D. Denton, J. Appl. Polym. Sci., 42, 75 (1991).

17. J. H. Jou, R. Huang, P. T. Huang, and W. P. Shen, J. Appl. Polym. Sci., 43, 857 (1991)

18. H. M. Tong and K. L. Saenger, J. Appl. Polym. Sci., 38, 937 (1989).

19. C. Feger, M. M. Khojasteh, and M. S. Htoo, "Advances in Polyimide Science and Technology," Technomic, Lancaster, PA, 1993.

20. J. G. Van Alsten and J. C. Coburn, Macromolecules, 27, 3746 (1994).

21. J. Crank, "The Mathematics of Diffusion," Clarendon Press, Oxford, 1976.

22. J. Crank and G. S. Park, "Diffusion in Polymers," Academic Press, London, 1968.

23. I. Isoda, H. Shimada, M. Kochi, and H. Kambe, J. Polym. Sci., Polym. Phys., 19, 1293 (1981).

24. T. P. Russel, Polym. Eng. Sci., 24, 345 (1984)

25. T. P. Russell, J. Polym. Sci., Polym. Phys., 22, 1105 (1984).

26. K. A. Lokhandwala, S. M. Nadakatti, and S. A. Stern, J. Polym. Sci., Polym. Phys., 33, 965 (1995).

27. D. W. van Krevelen, "Properties of Polymers," 3rd ed, Elserviers Science Inc., Amsterdam, 1990.

28. B. D. Cullity, "Elements of X-Ray Diffraction," 2nd ed, Addison-Wesley Publisher Co., Inc., London, 1977. 